\title{
O ponto de vista cria o objeto: a base da pesquisa em Linguística
}

\author{
The point of view creates the object: the basis of research in Linguistics \\ El punto de vista crea el objeto: la base de la investigación en Lingüística \\ Cláudio Primo Delanoy $\mathbb{C}$ \\ Pontifícia Universidade Católica do Rio Grande do Sul, Porto Alegre, RS, Brasil.
}

$\mathrm{C}$ omo é sabido, a linguagem humana é investigada desde o tempo das civilizações mais antigas. Dos supostos gestuais comunicativos pré-históricos, passando pelos cantos ritualísticos tribais, a linguagem acha-se como fundante da sociedade humana e, por isso, desperta tanto o nosso interesse. Se, conforme nos diz Benveniste, "Língua e sociedade não se concebem uma sem a outra" (2005, p. 31), estudar a linguagem é também estudar a sociedade. No entanto, as reflexões sobre a linguagem tiveram motivações variadas, nem sempre com viés científico. Novamente citando Benveniste "Vista d'olhos sobre o desenvolvimento da linguística",

Durante séculos, dos pré-socráticos aos estóicos e aos alexandrinos, e depois no renascimento aristotélico que estende o pensamento grego até o fim da idade média latina, a língua permaneceu objeto de especulação, não de observação (BENVENISTE, 2005, p. 20).

O linguista sírio naturalizado francês explica-nos que o estudo da linguagem até o século XVIII caracterizou-se como um meio para considerações filosóficas e históricas, mas não como investigação científica, quer dizer, o estudo da linguagem por ela mesma. Já no século XIX, com a descoberta do sânscrito, pesquisadores assumem um caráter comparatista de gramáticas, visando o estabelecimento de famílias linguísticas e suas evoluções diacrônicas. Na primeira década do século XX, datamos o início da ciência linguística com a publicação do Curso de Linguística Geral (CLG), atribuído a Ferdinand de Saussure, em 1916. Nessa obra póstuma, os seus organizadores Charles Bally e Albert Sechehay, com a colaboração de Albert Riedlinger, sistematizam os três cursos de Linguística ministrados por Saussure na Universidade de Genebra entre 1907 e 1910.
Como nos escreve Benveniste,

A linguística entra então na sua terceira fase, a de hoje. Toma por objeto não a filosofia da linguagem nem a evolução das formas linguísticas mas, em primeiro lugar, a realidade intrínseca da língua, e visa a se constituir como ciência - formal, rigorosa, sistemática (BENVENISTE, 2005, p. 21).

Estão lançadas as bases da Linguística científica moderna, com o estabelecimento de objeto e de método próprios de pesquisa. Até os dias atuais, a Linguística é devedora de Saussure, por mais que existam propostas teóricas diversas e até mesmo contrárias ao pensamento saussuriano, mas que somente foram possíveis porque dialogaram com os achados do mestre genebrino.

Particularmente, chama-nos a atenção uma das reflexões de base presente no CLG, fundamental para a construção do pensamento científico sobre a língua/linguagem. No capítulo "Objeto da linguística" (SAUSSURE, 2004, p. 15), encontramos: "Bem longe de dizer que o objeto precede o ponto de vista, diríamos que é o ponto de vista que cria o objeto". Tal pensamento demonstra a particularidade da concepção do objeto de estudo da linguagem, que difere daquele das denominadas ciências exatas e naturais. Para essas, o objeto é dado pelo mundo. Encontramos um inseto na floresta amazônica ainda não catalogado na Biologia, deparamo-nos com uma nova partícula do átomo resultante da explosão de outras partículas atômicas, ou surpreendemo-nos com uma mutação de um vírus. Todos esses objetos de estudo estão presentes no mundo, disponíveis para nossas pesquisas. Nada disso acontece com a linguagem. Ela não se manifesta isoladamente do ser humano, não esbarramos em linguagem. No entanto, a sua natureza interdependente 
do ser humano, e, portanto, complexa, não a impede de ter o seu objeto delimitado, mas com a necessidade de ser concebido pelo investigador.

Nesse processo de criação reside a afirmação de Saussure: o pesquisador vai criar o objeto a partir de um lugar, de uma ótica específica, que resultará em um objeto específico segundo dada perspectiva. Se olhamos a linguagem enquanto um sistema de signos relacionados, como o fez Saussure, ou se a concebemos como resultado de nossa biologia genética, como o fez Chomsky (1995), claramente obteremos resultados de pesquisas distintos, cada um concernente a sua base teórica, dentre outras possibilidades. Tomada uma decisão teórico-metodológica, desenrolam-se particularidades no processo investigativo. A fim de ilustração, citamos Volóchinov:

Para observar o fenômeno da língua, é necessário colocar os sujeitos falante e ouvinte, bem como o próprio som, no ambiente social. [...].

Desse modo, a unidade do meio social e do acontecimento da comunicação social mais próximo são duas condições totalmente necessárias para que o conjunto físico-psicofisiológico apontado por nós possa ter uma relação com a língua, com o discurso, possa tornar-se um fato da língua-discurso (linguagem) (VOLÓCHINOV, 2017, p. 145, grifo do autor).

Em sua perspectiva dialógica como fundante da linguagem, participantes do Círculo de Bakhtin, dentre eles Volóchinov, tomam o enunciado como unidade de pesquisa linguística, delimitado a partir do uso real da linguagem entre um falante e um ouvinte situados histórica e socialmente. A referida abordagem distinguese das áreas mais formais da Linguística justamente por considerar as influências ideológicas e culturais tanto na produção quanto na compreensão de discursos. Dessa forma, os resultados de uma pesquisa com base na teoria dialógica do discurso serão forçosamente distintos de uma pesquisa de viés sintático gerativista, mesmo que tenham dados linguísticos como corpus.

Tal diversidade na ciência Linguística se justifica pela própria complexidade da linguagem, impossível de ser restrita a um único viés teórico investigativo. É por isso que a Linguística se apresenta tão heterogênea em suas mais diversas áreas.

Da formalização sistemática da língua aos estudos do discurso, passando pelas relações interdisciplinares (medicina, física, psicologia, sociologia etc.), a Linguística avança em seu poder descritivo e explicativo. Pesquisadores partem de teorias da linguagem que lhes instrumentam metodologicamente e, ao aplicá-las, colaboram com o desvelar da natureza da linguagem. Podemos, assim, perceber que a afirmação saussuriana de que o ponto de vista cria o objeto pode ser aplicada a todas as pesquisas sobre linguagem, não somente as de cunho estruturalista. Cada área de estudo, seja morfologia, sintaxe, fonologia, semântica, enunciação, em suas mais diversas especificidades, todas circunscrevem as suas unidades de análise a partir de dada concepção teórica previamente eleita. Visto assim, tentamos justificar o título deste texto.

Neste número de sessão livre da Letras de Hoje, disponibilizamos algumas dessas pesquisas. Embora nos trabalhos aqui constantes predominem temas embasados em teorias do discurso, também apresentamos artigos voltados ao ensino e à aprendizagem de leitura, políticas linguísticas, escrita acadêmica e ensino e variação linguística. Vamos a eles.

Letícia Santana Gomes em "Lusofonias editoriais: os possíveis ethé discursivos de editores independentes" discute as imagens produzidas pelo discurso que editores independentes fazem de si em um documentário de autoria da própria pesquisadora. A partir de três entrevistas, com um editor moçambicano, um brasileiro e outro português, a autora chega a representações coletivas e individuais de ethé relacionados a editores independentes lusófonos. Tais representações vinculam o ofício da edição a projetos de vida, como uma forma de resposta a imaginários lusófonos característicos de Moçambique, Brasil e Portugal, e inquietações provocadas pela globalização cultural.

A pesquisa de Iverton Gessé Ribeiro Gonçalves, "Ethos discursivo e subjetividade no jornalismo: William Bonner em tempos eleitorais", versa sobre o discurso do referido apresentador de telejornal na época das eleições presidenciais de 2014. Seu objetivo é revelar o ethos do apresentador a partir de marcas discursivas de subjetividade em recortes de três entrevistas com candidatos à presidência. Para tanto, o autor buscou apoio teórico em Benveniste, do qual serviu-se do conceito de subjetividade na linguagem, e em Maingueneau, do qual utilizou os conceitos de cenografia e de ethos discursivo.

Já o artigo de Roseméri Lorenz e Luciana Maria Crestani, "O éthos e o páthos na publicidade da Dove: uma construção sincrética", concentra-se nos conceitos retóricos ethos e pathos para analisar dois anúncios publicitários de produtos de higiene. Seu objetivo é investigar como tais conceitos emergem da relação entre discursos verbais e não verbais presentes nos comerciais. Partindo da semiótica de Greimas, as pesquisadoras buscam descrever a atuação das imagens do enunciador e do enunciatário por meio de marcas enunciativas nos discursos.

O trabalho de Juliana Geórgia Gonçalves de Araújo e Lia Raquel Vieira de Andrade, "O dialogismo e a construção do ethos no discurso publicitário", 
estuda o poder de persuasão do ethos discursivo em diálogo com as reflexões bakhtinianas sobre discurso. Seu objeto de análise são discursos publicitários de sabão em pó, nos quais a elaboração do ethos aliada a determinadas cenografias, segundo o linguista Dominique Maingueneau, contribuem para captar a adesão do leitorconsumidor. Nesse caso, haveria um envolvimento do leitor-consumidor com o ethos criado a partir da personagem de uma mãe preocupada com a conservação das roupas dos filhos sem privá-los das brincadeiras.

Gustavo Estef Lino da Silveira, Poliana Coeli Costa Arantes e Bruno Deusdará assinam o artigo "Só o Zé Lador se lembra deles": ethos e novas formas de produzir notícia". No trabalho, os autores levantam a discussão sobre a influência das redes sociais, ambientes característicos de interação em veículos jornalísticos. Particularmente, a pesquisa concentra-se em uma seção específica de um jornal impresso em que a interação via Whatsapp é estimulada pelo jornal. No contexto de um espaço impresso destinado a manifestações dos leitores, é analisada a produção de ethos discursivo da empresa jornalística sob a perspectiva de Dominique Maingueneau.

Eliana Correia Brandão Gonçalves discute a formação do ethos da autoridade institucional do Império e da Província na Bahia do século XIX em "Construção discursiva do ethos da autoridade institucional: poder, vigilância e revoltas escravas na Bahia". O trabalho fundamenta-se em Maingueneau, Charaudeau e Amossy. Partindo do contexto das rebeliões escravas na Bahia, a autora busca na Resolução do Conselho Interino do Governo da Bahia de 28 de novembro de 1822, texto do acervo de Manuscritos da Biblioteca Nacional, no Rio de Janeiro, a construção do ethos de autoridade do governo frente às ameaças dos escravos rebeldes.

O trabalho de Mary Elizabeth Cerutti-Rizzatti e de Hellen Melo Pereira, "Linguística, educação e política: para além da academia", aborda as relações entre as três áreas constitutivas do título a partir de reflexões apoiadas em Geraldi, Moita-Lopes, Volóchinov e Vygotski, dentre outros. Seus questionamentos centram-se a respeito das reais contribuições da ciência da linguagem, a Linguística, para o ensino e a aprendizagem de Língua Portuguesa, e como esses estudos colaboram para a formação de nossos estudantes no contexto social brasileiro.

$\mathrm{O}$ artigo de Enrique Sologuren Insua e de María Natalia Castillo Fadic, "La construcción del ethos en informes de laboratorio producidos por estudiantes universitarios: contrastes en el discurso académico en español" destina-se a analisar as maneiras pelas quais estudantes universitários do terceiro ano de Engenharia Elétrica marcam-se no discurso e assim produzem imagens de si, revelando, assim, caracteres identitários. A fundamentação teórica dá-se na análise semiodiscursiva de Charaudeau, nos estudos de letramento crítico de Ivanic e nos estudos de discurso acadêmico de Hyland e Swales. As estratégias discursivas dos estudantes mostram modos de emergência do sujeito em suas produções textuais.

Maria Eduarda Giering e Eduardo Paré Glück desenvolveram a pesquisa "Ethos discursivo e o comportamento enunciativo: a construção de si de comentaristas de notícias de divulgação científica da revista Superinteressante on-line". O artigo, fundamentado nos modos de organização do discurso desenvolvidos por Charaudeau e nos conceitos de ethos propostos por Maingueneau e Amossy, investiga como os leitores da referida revista comportam-se discursivamente na formulação de uma cena de enunciação, de uma cenografia reveladora de um ethos discursivo em interação com o interlocutor.

O trabalho de Joana Cruz, Patrícia Constante, Elisa Lopes, Joana Amaral, Daniela Quintas e Maria José Mackaaij, intitulado “"A LER VAMOS...' e 'L.E.R. CÃOFIANTE': Eficácia de uma intervenção no 2o ano de escolaridade", tem como tema o ensino e a aprendizagem de leitura. A pesquisa relata o processo de intervenção em um grupo de estudantes em nível inicial com dificuldades de leitura por meio de um projeto de aprendizagem que envolveu o desenvolvimento de consciência fonológica, descodificação leitora e fluência, apoiadas em software específico. Dentre os pesquisadores citados como base teórica do estudo, ressaltam-se os autores que fundamentaram os instrumentos de análise: Sucena e Castro (provas ALEPE), Carvalho (teste REI), Monteiro, Mata e Peixoto (Escala de Autopercepção de Leitor) e Mata (Escala de Emoções).

Já o artigo "Colocaciones léxicas verbo-nominales en un corpus de aprendices de español como lengua extranjera de nivel A2 y B1", de Lorena Paulina Blanco San Martín, Anita Alejandra Ferreira Cabrera e Erwin Leonidas Blanco San Martín, apresenta como tema as colocações lexicais verbo-nominais simples do nível A2 e B1 em um subcorpus do Corpus de Aprendices de Español como Lengua Extranjera. Tem como finalidade um estudo descritivo de tais colocações lexicais verbo-nominais. Seguindo a metodologia da Linguística de Corpus, tal estudo se desenvolve no âmbito da Linguística Aplicada, no campo de Aquisição de Segunda Língua e de Espanhol como Língua Estrangeira.

$\mathrm{O}$ artigo "'Eu e meus alunos-cotistas na escola pública': racismo, ethos discursivo, discurso midiático e produção de subjetividade", que fecha este volume, de autoria de Bianca Assis Oliveira de Paula, Fabio Sampaio de Almeida e Maria Cristina Giorgi, teve equivocadamente a publicação de uma versão não atualizada pelos autores na edição da Letras de Hoje, v. 53, n. 3 (2018). A presente publicação, portanto, não é inédita, mas apresenta a versão final do trabalho dos referidos autores. 


\section{Referências}

BENVENISTE, Émile. Problemas de Linguística Geral I. Trad. Maria da Glória Novak e Maria Luisa Neri. Revisão prof. Isaac Nicolau Salum. Campinas: Pontes, 2005.

CHOMSKY, Noam. The minimalist program. Cambridge: The MIT Press, 1995.

SAUSSURE, Ferdinand de. Curso de Linguística Geral. (1916). BALLY, Charles; SECHEHAYE, Albert (org.). São Paulo: Cultrix, 2004.

VOLÓCHINOV, Valentin. Marxismo e Filosofia da Linguagem: problemas fundamentais do método sociológico na ciência da linguagem. (1929). Trad. Sheila Grillo e Ekaterina Vólkova Américo. São Paulo: 34, 2017. https://doi. org/10.1590/2176-457336646

Recebido em: 31/10/2019

Aprovado em: 31/10/2019.

Publicado em: 23/12/2019.

Autor:

Cláudio Primo Delanoy

Doutor em Letras, professor da Pontifícia Universidade Católica do Rio Grande do Sul, Porto Alegre, RS, Brasil.

Orcid: https://orcid.org/0000-0002-8015-5349

E-mail: claudio.delanoy@pucrs.br

Endereço: Av. Ipiranga, 6681, Prédio 8 - Partenon

90619-900, Porto Alegre, RS, Brasil 